\title{
Rescate: Reseña del libro de Daniel Alejandro Capano, Dino Buzzati: Una metafísica de lo fantástico
}

Capano, Daniel Alejandro. (2015). Dino Buzzati: Una metafísica de lo fantástico. Buenos Aires: Biblos, 194 Págs., ISBN: 978-987-691-320-1.

Daniel Del Percio ${ }^{1}$ Universidad de Palermo - CICS

Material original autorizado para su primera publicación en el Journal de Ciencias Sociales, Revista Académica de la Facultad de Ciencias Sociales de la Universidad de Palermo.

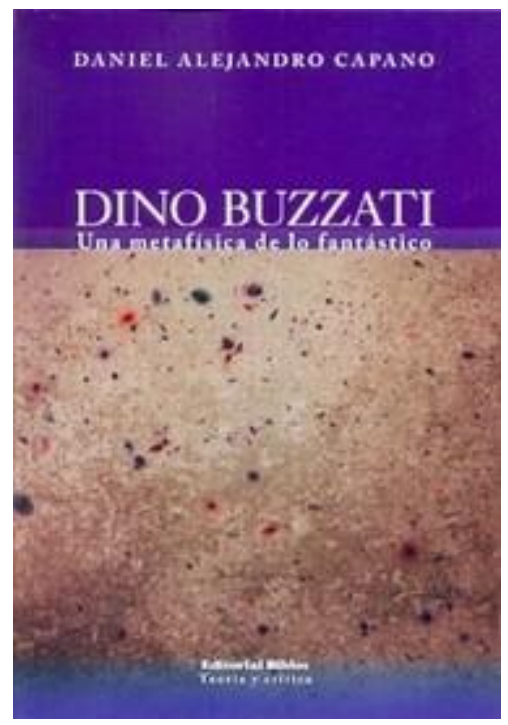

Para pensar la realidad suelen ser necesarias las paradojas, una propiedad esencial de lo fantástico. Por tanto, rescatar la obra de un autor paradigmático del género como Dino Buzzati merece una atención especial, más pensando en el "olvido" que las editoriales argentinas tienen sobre la obra de este célebre autor italiano nacido en San Pellegrino, en 1906 y muerto en 1972 en Milán.

En este panorama encontramos felizmente el reciente libro del Doctor Daniel Alejandro Capano, Dino Buzzati: Una metafísica de lo fantástico, en donde desarrolla una exhaustiva investigación sobre este célebre narrador, autor de teatro e historietista, que ha sido comparado con Kafka y que posee fuertes vínculos con la obra de Borges. Este estudio no se limita a su narrativa, ya sólo disponible en nuestro medio en escasas ediciones españolas, sino que establece fluidos vasos comunicantes con la filosofía,

\footnotetext{
${ }^{1}$ Doctor en Letras, Magíster en Diversidad Cultural. Docente e investigador en el CICS, Universidad de Palermo. mail: ddelpercio1@gmail.com
} 
particularmente Henri Bergson y Martin Heidegger, con el cine y las artes plásticas, y con otras literaturas, en especial la argentina, a la que le dedicará un capítulo específico.

Daniel Capano es Licenciado en Letras por la Universidad de Buenos Aires y Doctor en Letras por la Universidad del Salvador. Investigador institucional en el Centro de Literatura Comparada María Teresa Maiorana (UCA) y Profesor consulto y miembro de la Comisión de Investigación del Doctorado en Letras (USAL), también es miembro fundador y vicepresidente del Centro de Estudios de Narratología. Es autor, además de una interesante y numerosa colección de artículos y de diversos trabajos publicados en antologías, de tres libros completos: El errático juego de la imaginación. La poética de Antonio Tabucchi (2007), Constelaciones textuales. Escritos de literatura comparada (italianística) (2009) y Narradores sicilianos contemporáneos (Bufalino, Consolo, Lampedusa, Sciascia) (2011). Estos antecedentes no constituyen sólo una presentación del autor, sino que caracterizan con claridad el mismo desarrollo de su investigación. En efecto, la lectura del índice nos aporta referencias a los distintos núcleos que articulan este trabajo con un enfoque claramente interdisciplinario.

El capítulo primero aborda la compleja (y polémica) problematización de la naturaleza del propio discurso fantástico, de su delimitación y características. Con gran poder de síntesis, el autor recorre las teorías más importantes sobre esta elusiva materia, desde las ya clásicas de Louis Vax, Ana María Barrenechea y Tzvetan Todorov hasta las más modernas teorizaciones del Fantasy de Rosemary Jackson y Jean Bessière, sin desdeñar los estudios más propios de la ciencia ficción de Darko Suvin. Pero en esta indagación, no se limita a los análisis específicamente literarios, ya que revisa la concepción de lo fantástico en Jean Paul Sartre, y de lo siniestro en Sigmund Freud y en Jacques Lacan. Este recorrido se cierra con los aportes del ensayista argentino Jaime Alazraki y su análisis de La Metamorfosis de Franz Kafka, en donde define lo que denomina "neofantástico", en donde las concepciones tradicionales aparecen atravesadas por los aportes de las Vanguardias del siglo XX, los efectos de la Primera Guerra Mundial, y los aportes del psicoanálisis, al punto de insertarse en una visión propia de la Posmodernidad.

El segundo capítulo aborda otro problema, no menor con respecto al anterior, y con inevitables lecturas sociológicas: el desarrollo de la literatura fantástica en Italia. El análisis del campo intelectual italiano entre ambas guerras mundiales, con el contexto opresivo y nacionalista del fascismo, describe un espacio de debates y de una esperanzada búsqueda que llevan adelante distintos escritores por asimilar, desde la cultura italiana, los importantes aportes de otras literaturas, como la francesa y la norteamericana. La breve pero consistente historia que traza el profesor Capano de las distintas revistas literarias de la época ( $L a$ Ronda, Solaria y Novecento), evidencia estos conflictos, complementados con una síntesis de los más significativos autores de literatura fantástica italianos, desde el siglo XIX (Boito, Nievo, Fogazzaro) hasta bien 
entrado el siglo XX (el propio Buzzati, Bontempelli, Landolfi, Wilcock, Italo Calvino), y su desarrollo posterior hasta la actualidad en sus autores más sobresalientes (Tabucchi, Maurensig, Pazzi, Baricco y Paola Capriolo). "El universo narrativo de Dino Buzzati" es el capítulo en el que se ocupa de articular los dos problemas planteados anteriormente con la especifica poética del autor italiano, que de acuerdo con el análisis del profesor Capano incluye, además de una "metafísica del paisaje", lo onírico, el absurdo y la ciencia ficción. Estos núcleos de significación son tratados en una sintética revisión de toda la obra del autor, que luego profundizará en los dos capítulos siguientes.

Dada la importancia, no sólo dentro de su obra sino en el contexto de la literatura fantástica del siglo XX, de la novela de Buzzati /l deserto dei tartari (a la que el propio Jorge Luis Borges considera uno de los clásicos contemporáneos), "La poética espacio-temporal de El desierto de los tártaros" constituye el cuarto (y uno de los más extensos) capítulos del libro. En efecto, la problematización del tiempo y del espacio constituye el eje central del análisis que se despliega desde lo filosófico (la impronta de Martin Heidegger, Max Planck y Henri Bergson, entre otros) y desde las modernas teorías de la narrativa (Roland Barthes, Umberto Eco, Gerard Genette, entre otros).

El capítulo 5, "Fantasía y existencia en los cuentos de Buzzati”, es el más extenso y variado, y el que permite a su vez recorrer en el tiempo las variaciones temáticas, estilísticas y poéticas del autor italiano, ya que el profesor Capano realiza una exhaustiva taxonomía de la producción cuentística (sobre el espacio, el tiempo y sus variantes narrativas, sobre los personajes y las distintas recurrencias temáticas, como la cábala, la numerología, la metamorfosis, la enfermedad, la memoria, la postura antibélica.), a la que sigue una no menos detallada revisión de los textos en sí a la luz de esta taxonomía. Destacamos de este análisis los que realiza sobre "I sette messaggeri" ("Los siete mensajeros") desde la tipología de la "fuga del tiempo", "Sette piani" ("Siete pisos") desde la tipología de la enfermedad, y "Paura alla Scala" ("Miedo en la Scala") desde los estados psíquicos alterados. Lo zoomórfico y la metamorfosis, muchas veces en clave de ciencia ficción, otras, más cercanas a lo maravilloso (como en "Il colombre") y la postura antibélica ("All'idrogeno") completan este riguroso panorama.

"Buzzati, entre la pintura y la escritura" constituye uno de los más interesantes aportes del libro, ya que la obra pictórica del autor belunés, si bien no es desconocida, ha sido poco estudiada a un nivel académico. Es de destacar aquí especialmente su análisis de Poema a fumetti (editado en español por la editorial Gadir con el título Poema en viñetas), adaptación a través del lenguaje híbrido propio de la novela gráfica del mito clásico de Orfeo y Eurídice. Las virtudes como pintor de Buzzati, como observa el profesor Capano, son tan amplias y sofisticadas que abarcan incluso la capacidad de ilustrar libros infantiles y las obras de otros autores, naturalmente afines a él, como el propio Franz Kafka (La metamorfosis). 
El vínculo de Buzzati con las letras argentinas es el tema del último capítulo. Desde el campo de la literatura comparada, en el cual posee vasta experiencia (esta focalización la ha adoptado en mayor o menor grado en sus tres libros anteriores) Daniel Capano explora estas relaciones en la obra de Jorge Luis Borges (acaso quién más correspondencias posee con el autor italiano), Adolfo Bioy Casares, Julio Cortázar y Guillermo Martínez.

El libro se cierra con un Post Scriptum a manera de conclusión, un breve pero sentido perfil de este autor fascinante que, además, fue un periodista excepcional, y corresponsal de guerra durante la Segunda Guerra Mundial, y una detallada cronología de su vida y obra. La bibliografía citada es un aporte en sí misma, al presentar textos poco conocidos en nuestro país.

Esbozar las líneas esenciales de un escritor tan singular no es tarea sencilla. Debemos decir que no pecamos por exceso al afirmar que el libro del Doctor Daniel Capano es imprescindible para todo aquel estudiante, profesional, investigador o simplemente lector curioso que desee conocer y comprender la obra integral de ese autor genial que se llamó Dino Buzzati, textos que aún nos estremecen con sus fantasmagorías y sus muchas veces delirantes pero siempre equilibrados mundos ficcionales. 